\title{
Annie Crépin, Jean-Pierre Jessenne et Hervé Leuwers (dir), Civils, citoyens-soldats et militaires dans l'État-Nation (1789-1815)
}

Actes du colloque d'Arras des 7 et 8 novembre 2003, Paris, Société des études robespierristes, collection études révolutionnaires $n^{\circ} 8,2006,175$ p., ISBN 2-908327-53-8, $25 €$.

Philippe Catros

\section{(2) OpenEdition}

1 Journals

Édition électronique

URL : https://journals.openedition.org/ahrf/11298

DOI : 10.4000/ahrf.11298

ISSN : 1952-403X

Éditeur :

Armand Colin, Société des études robespierristes

Édition imprimée

Date de publication : 1 septembre 2007

Pagination : 222-224

ISSN : 0003-4436

\section{Référence électronique}

Philippe Catros, «Annie Crépin, Jean-Pierre Jessenne et Hervé Leuwers (dir), Civils, citoyens-soldats et militaires dans l'État-Nation (1789-1815) », Annales historiques de la Révolution française [En ligne], 349 | juillet-septembre 2007, mis en ligne le 29 décembre 2009, consulté le 01 juillet 2021. URL : http:// journals.openedition.org/ahrf/11298; DOI : https://doi.org/10.4000/ahrf.11298 
Annie Crépin, Jean-Pierre Jessenne et Hervé Leuwers (dir.), Civils, citoyens-soldats et militaires dans l'État-Nation (1789-1815), Actes du colloque d'Arras des 7 et 8 novembre 2003, Paris, Société des études robespierristes, collection études révolutionnaires $\mathrm{n}^{\circ} 8,2006,175$ p., ISBN 2-908327-53-8, $25 €$.

Comme le soulignent Jean-Pierre Jessenne et Hervé Leuwers dans leur avant-propos, ce colloque s'est fixé comme ambition de favoriser un bilan des recherches sur les rapports entre société civile et société militaire à l'époque révolutionnaire et napoléonienne. Deux types de communications s'y côtoient : des

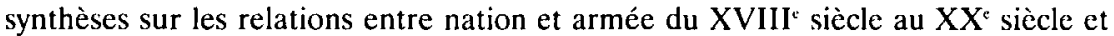
des études de cas, le plus souvent menées par des chercheurs en cours de thèse ou venant de l'achever.

Louvrage s'ouvre et s'achève par deux synthèses générales. Annie Crépin offre un bilan des grands axes et des principaux chantiers de la recherche à travers l'analyse des « nouvelles tendances de l'historiographie militaire de la Révolution et de l'Empire ". De même, dans " Nation et armée aux XIX" et XX" siècles ", Allain Bernède présente l'évolution général du recrutement militaire de la loi Gouvion Saint-Cyr de 1818 qui restaure une "conscription masquée " à la suppression du service national en 1996. Autre communication à vocation générale, celle de Thomas Hippler qui, dans « l'État, le citoyen, l'armée : volontariat et contrôle social », montre l'apparent paradoxe du service militaire. Dénoncé comme un " esclavage militaire " avant 1789 , il devient, à partir de la Révolution, une des premières expressions de la citoyenneté.

D'autres communications proposent des synthèses régionales des rapports entre société civile et société militaire. C'est le cas de Jean-Pierre Jessenne et Hervé Leuwers dans «Armée et société au Nord (1789-1815) "-c'est-à-dire au sein d'un espace septentrional compris entre Seine et Flandre -, de Jean-Paul Rothiot dans “ Armée et nation dans la France de l'Est » ou encore de Jacques Bernet dans « Armée et société sous la Révolution et l'Empire en Champagne et en Picardie ». Ces régions frontalières et « patriotes ", dans lesquelles la présence militaire était déjà forte avant la Révolution, ont en commun de répondre favorablement aux premières levées révolutionnaires. La levée des 300000 hommes suscite quelques résistances, de même que la conscription napoléonienne, cependant l'insoumission n'est pas très importante, à l'exception peut-être des dernières levées impériales. Ce constat général permet à Jean-Pierre Jessenne et Hervé Leuwers de parler d'" une sorte de " familiarisation" à la conscription ". Il n'en demeure pas moins que beaucoup de conscrits, et leur famille, usent du remplacement ou cherchent à se faire exempter - les pratiques de corruption étant sans doute nombreuses. Dans bien des cas les jeunes rejoignent l'armée sans enthousiasme, ce qui pousse Jacques Bernet à se demander jusqu'à quel point la présentation de l'acceptation du service militaire comme modèle de civisme à la française ne relève pas d'un mythe. Dans ces mêmes régions les nombreuses réquisitions militaires ne soulèvent pas non plus d'opposition massive. Jean-Paul Rothiot souligne à cet égard le rôle joué par les administrations départementales et communales, voire par les sociétés populaires, pour soutenir et organiser l'effort de guerre.

Comme le remarque Vincent Cuvilliers, dans « La mise en scène de l'armée par les autorités administratives " à travers l'exemple du Pas-de-Calais, la propagande révolutionnaire s'efforce de rapprocher armée et société. S'adressant autant aux civils qu'aux soldats, les autorités tentent de démontrer à la fois que l'armée est 
partie intégrante de la nation et qu'elle a pour mission sacrée de défendre la patrie. Cette propagande révolutionnaire est également l'œuvre des sociétés populaires. C'est ce que montre Bruno Ciotti dans son étude sur "Les sociétés populaires du Puy-de-Dôme et les recrutements militaires (1791-an III) ". Il relève une corrélation entre les communes dans lesquelles il cxiste des sociétés populaires et celles où les volontaires sont les plus nombreux en 1791 et 1792. Cependant peu de membres des sociétés populaires rejoignent les armées ; ils préfèrent servir d'auxiliaires aux autorités civiles dans la mise en œuvre du recrutement, dans l'aide aux familles des soldats, ou encore dans la traque des embusqués et des insoumis. Pour Nathalie Alzas qui analyse « les rapports entre civils et militaires à l'arric̀re pendant la Révolution dans les départements du Midi ", le rôle des autorités civiles est également fondamental dans l'organisation de l'effort de guerre. À cet effet, elle souligne que les autorités militaires sont toujours subordonnées aux autorités civiles : encadré par les administrations civiles, l'effort de guerre de la Révolution se fait dans un cadre juridique qui tente de préserver les populations des abus du pouvoir militaire. Phénomène nouveau, il contribue à une meilleure intégration des militaires dans la société civile et il favorise aussi le développement d'une économie de guerre. Cette nouvelle synergie entre société militaire et société civile se voit également par la place que prend la gendarmerie dans le maintien de l'ordre. C'est ce que montre Franck Vandeweghe dans sa communication sur "Les gendarmes représentants l'armée auprès des populations briardes (1791-1814)".

Enfin, diverses communications abordent plus spécifiquement la société militaire. Dans « La délinquance militaire dans les départements du Nord et du Pas-de-Calais du Directoire aux premières années de l'Empire (1795-1805) ", Nicolas Cadet s'intéresse au fonctionnement de la justice militaire. Il constate entre autres que les atteintes aux biens sont plus sévèrement condamnées que les atteintes aux personnes et que les tribunaux militaires sont relativement cléments à l'égard de soldats coupables de violences envers les civils. Dans \& Les nouveaux Français et l'armée dans les départements du Léman et du Mont-Blanc » qui viennent d'être rattachés à la Grande Nation, Sylvain Sick prolonge l'étude de la conscription par une analyse de la mentalité des jeunes recrues à travers leur correspondance. Didier Michel cible plus particulièrement le rapport entre « Citoyenneté et politique dans la correspondance d'un officier de l'Ouest (1788-1792) ", le chevalier Blondel de Nouainville qui obtint une notoriété nationale quand, à Rennes, en 1788 , il s'interposa entre sa troupe et des émeutiers afin d'éviter tout affrontement. Devenu une sorte d'icône du soldat citoyen à la veille de la Révolution, il aura pourtant bien du mal à accepter cette dernière et finira par émigrer durant l'hiver 1792-1793. Cette attitude est partagée par bon nombre d'officicrs ainsi que l'explique Olivier Paradis dans «De la difficulté à vivre ses choix politiques : les jeunes officiers de l'armée, du service du roi à celui de l'empereur ». Son étude porte sur un corpus d'officiers, à $90 \%$ nobles, sortis de l'école royale militaire d'Effiat entre 1777 et 1791 . En 1794, 10\% seulement sont demeurés fidèles à la Révolution; et ils sont sans doute plus animés par le désir de servir leur patrie que par la cause révolutionnaire. Quant à ceux qui ont émigré, une bonne partie reprend du service sous l'Empire mais leur ralliement est sans conviction et beaucoup applaudissent le retour de la monarchie. Cependant la majeure partie des cadres de l'armée napoléonienne ne poursuit pas son service au-delà de 1815. C'est ce que montre Angelo Celeri dans « Des armées de la Rćvolution et de l'Empire aux médaillés de Sainte-Hélène : carrières militaires à travers l'exemple de l'Eure ». 
Créée en 1857 la médaille de Sainte-Hélène était réservée aux anciens soldats napoléoniens. Étudiant les dossiers constitués par ceux qui la réclamèrent, Angelo Celeri montre entre autres que la plupart des médaillés de l'Eure ont connu une carrière sans éclat et que les promotions militaires ont souvent été lentes.

Par la richesse et la diversité des études proposées, les actes de ce colloque témoignent donc du renouveau et de la vitalité de l'histoire militaire de la Révolution et de l'Empire. Loin de l'histoire-bataille ou de la geste impériale, ces multiples chantiers prouvent que l'histoire militaire et l'histoire du militaire sont indispensables pour mieux comprendre la France de la Révolution et de l'Empire.

Philippe Catros

Julien GuÉrin, Solon Reynaud (1749-1815), Polignac, Éditions du Roure, 2007, 120 p., ISBN 978-2-906278-66-0, $12 €$.

Ce petit ouvrage est issu d'un mémoire de maîtrise soutenu en 2004 à l'Université de Clermont-Ferrand, sous la direction de Philippe Bourdin, par Julien Guérin, désormais jeune professeur d'histoire. Il vient ajouter à la galerie des portraits de représentants du peuple celui de Claude André Benoit Reynaud qui, à partir de janvier 1794, choisit le prénom de Solon. Sur Solon Reynaud comme sur tant d'autres bien sûr, dominaient jusqu'ici des écrits se rattachant à une historiographie très hostile à la Révolution française, tel celui de "sœur Marie-Pascale " qui fêta à sa manière le Bicentenaire en 1989 avec un « Petit Précis ou petite et faible esquisse de l'affreux tableau de la funeste Révolution de France, qui éclata en 1791 sous le règne de Louis XVI, dont ce bon roi fut la victime "... on appréciera à sa juste valcur ce long titre, force étant d'espérer que la religieuse ait pu au moins gagner quelque indulgence grâce à lui. Le présent ouvrage vient fort à propos donner une tout autre approche biographique de Reynaud et propose une étude centrée avant tout sur sa longue mission en Haute-Loire entre la fin de l'été 1793 et le printemps 1794.

Né en 1749 au Puy dans une famille apparemment aisée - sans cependant que des précisions chiffrées soient apportées ici -, avec un père anobli, Reynaud s'engage dans la Révolution en 1790 en devenant officier municipal (en février) puis maire de sa ville natale (en août). Au terme d'un parcours typique de nombre de ces notables provinciaux, il est élu à la Législative en 1791. Il y prend peu la parole, mais entretient en revanche une correspondance active avec la société populaire du Puy. En septembre 1792, il est " réélu " et devient l'un des sept représentants envoyés à la Convention par la Haute-Loire, le premier élu des sept avec 219 voix sur 334. Montagnard, toujours plutôt effacé dans l'Assemblée, régicide, il est choisi le 9 mars 1793 pour accompagner Lacoste en Haute-Loire et dans le Cantal afin d'y accélérer la levée des 300000 hommes. Néanmoins, quelques jours après, il est remplacé par Faure, lui aussi élu de Haute-Loire. Pourquoi ? On ne le savait pas et hélas le mystère reste toujours entier à la lecture de cette biographie. Quoi qu'il en soit, c'est donc à la fin d'août qu'il obtient sa première (et seule) mission, dans le cadre cette fois de la levée en masse qu'il est chargé de surveiller en Haute-Loire et Lozère (plus des départements " environnants"). Le 7 septembre, il arrive au Puy et va y rester de longs mois, une incursion à Lyon mise à part, au cours de laquelle il assiste en octobre à la reprise de la ville assiégée. 